\title{
Investigation of mechanical properties of lime- sand brick under dynamic loading
}

\author{
Anatoliy Bragov ${ }^{1, *}$, Andrey Lomunov ${ }^{1}$, Alexander Konstantinov ${ }^{1}$, Dmitriy Lamzin ${ }^{1}$, \\ and Leopold Kruszka ${ }^{2}$ \\ ${ }^{1}$ Research Institute of Mechanics, Lobachevsky National State Nizhny Novgorod Research \\ University, Gagarin Ave., 23, bldg. 6, 603600, Russian Federation \\ ${ }^{2}$ MilitaryUniversity of Technology, 2 Gen. Witolda Urbanowicza Street, 00-908 Warsaw, Poland
}

\begin{abstract}
The results of experimental study of mechanical properties of samples of lime-sand brick under dynamic loading are presented. The tests were carried out using the traditional Kolsky method and its modification dynamic splitting (the so-called «Brazilian test»). The laws of change in strength, strain, time properties and energy intensity of the investigated material are established in the strain rate range of $5 \cdot 10^{2}-2.5 \cdot 10^{3} \mathrm{~s}^{-1}$ under compression and in the stress rate range of $2 \cdot 10^{1}-3 \cdot 10^{2} \mathrm{GPa} / \mathrm{s}$ under tension.
\end{abstract}

\section{Introduction}

Investigation of the mechanical properties of building materials subjected to dynamically applied loads is relevant in up-to-date engineering science due to the increase in number of various types of emergencies (natural disasters, technological accidents, terrorist acts, etc.). Such tragedies are accompanied by the intense impacts and explosions which are characterized by continuous variation of parameters, high intensity and short duration. In addition, the design and construction of industrial facilities have been developed actively in recent years, during the service of which a variety of dynamic effects on the structure occur. Multipurpose programs of finite element analysis such as ANSYS, NASTRAN, LS-DYNA, ABAQUS and others are widely used in the modern design and calculation of building structures. Herewith, it is necessary to lay in calculation of the mechanical characteristics of the material which will determine the behavior of the simulated structure under loading. Experimentally obtained mechanical properties of materials for various types of stressstrain state are also necessary for constructing ultimate surfaces (yield surface, fracture surface, etc.) in order to develop new hypotheses of dynamic strength and to test the existing ones. Therefore, studying the behaviour of modern building materials under dynamic loading is becoming topical.

There is a large number of publications about the behaviour of brittle materials (concrete, fiber-reinforced concrete, rocks) under dynamic loading, for example, [1-5] and others. However, the behavior of the brick at high strain rates has not been investigated yet. Therefore, an experimental study of the dynamic behaviour of lime-sand brick grade 150

\footnotetext{
* Corresponding author: bragov@mech.unn.ru
} 
was carried out. The experiments were conducted at the facilities that implement the classical Kolsky method for compression tests under uniaxial stress state conditions at high strain rates. In addition, a modification of this technique - dynamic splitting (the so-called «Brazilian test») was used to determine the properties of the material under tension. As a result of these experiments the deformation diagrams were constructed at different dynamic impact regimes; strength, strain, time and energy characteristics were obtained as well as their dependence on strain rate or stress rate. The influence of strain rate and stress rate on the properties of the tested material is noted.

\section{Making samples}

Samples were made in the form of cylinders with a diameter of $20 \mathrm{~mm}$ and a length of 10 $\mathrm{mm}$ for compression tests and a length of $20 \mathrm{~mm}$ for tensile tests (splitting tests). At first, the plates of $10 \mathrm{~mm}$ and $20 \mathrm{~mm}$ thick were cut off from bricks on a stone-cutting machine with a diamond disc and then cylindrical samples were drilled from these plates for experiments on a drilling machine with a diamond-coated crown.

\section{Dynamic test methods and experimental setup}

Among the known methods of dynamic testing of materials the Kolsky method with the Split Hopkinson pressure bar (SHPB) [6] was most widely used due to its good theoretical validity and simplicity of implementation. Numerous modifications of this technique have been developed by now, for example [7-11], the techniques which allow to determine the various mechanical properties of materials at high strain rates. In this paper the classical Kolsky method was used to determine the strength of samples of lime-sand brick under uniaxial compression and its modification the «Brazilian test» (splitting test) [11] which is an analogue of the tensile testing scheme (Fig. 1).

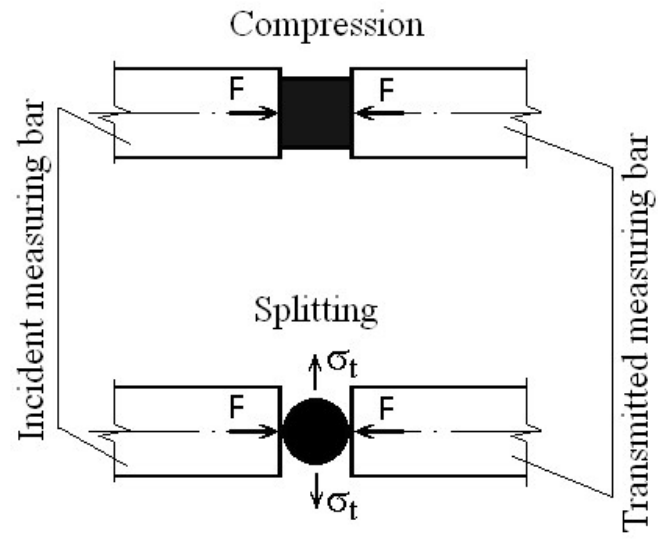

Fig. 1. Techniques used in dynamic testing of lime-sand brick.

The setup for dynamic tests consisted of a pneumatic loading device - a gas gun with a control system, a complex of measuring and recording equipment and a replacement set of measuring bars with a diameter of $20 \mathrm{~mm}$. The registration of initial experimental data was carried out using strain gauges glued on the lateral surface of measuring bars, signals from which were transferred to a digital storage oscilloscope using schemes of dynamic tensometry. Then the oscillograms were saved digitally and processed using the original software. 


\section{Results of dynamic tests on uniaxial compression}

Dynamic compression tests under one-dimensional stress state were carried out on cylindrical samples with a diameter of $20 \mathrm{~mm}$ and a length of $10 \mathrm{~mm}$. Cylindrical bars with a diameter of $20 \mathrm{~mm}$ and a length of $300 \mathrm{~mm}$ were used as strikers. The change in the amplitude of the loading wave was achieved by the alteration of the velocity of the striker. Herewith, such loading regimes were achieved that the sample was destroyed completely into pieces and even «into dust».

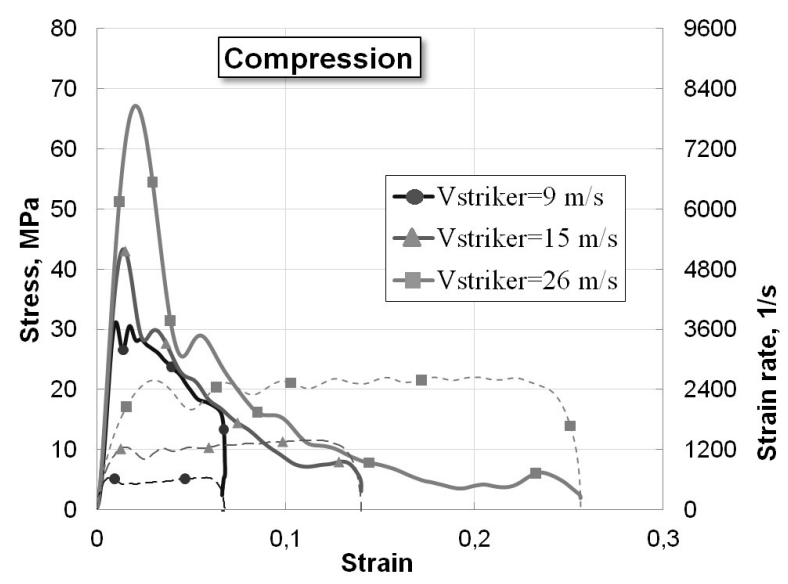

a

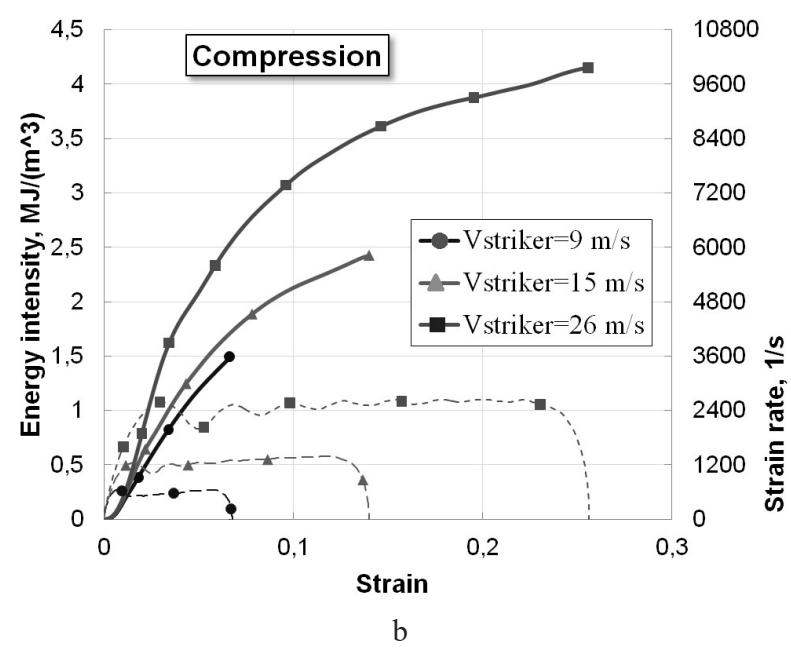

Fig. 2. Deformation diagrams (a) and graphs of the energy intensity (b) of samples of lime-sand brick under compression

Dynamic tests are performed when the sample is loaded with an intense pulse shortterm loading which can cause inhomogeneous stress state of the sample due to the propagation of stress waves in it and considerable inertial forces can also affect the sample. The results of the investigations and some of the recommendations for brittle material described in [12-14] were taken into account in order to fulfil the basic premise of the Kolsky method that is the realization of an uniaxial stress state with an uniform distribution of stresses and strains along its length. Thus, the ratio of the length to the diameter of the samples was within the recommended limits of 0.3-1.0. A thin layer of grease was applied 
to the ends of the measuring bars before testing in order to reduce the influence of frictional forces during the radial expansion of the sample. An analysis of time history of the synchronized pulses of strain of the measuring bars has shown that the forces at the ends of the sample are practically equal and the state of its equilibrium deformation is achieved.

Compression tests were carried out in order to investigate the influence of the strain rate on the deformation diagram, strength, strain and energy intensity prior to fracture of limesand brick. Fig. 2a shows the average deformation diagrams with strain rate history obtained at various regimes of dynamic loading of the samples. The solid lines show the stress dependences versus strain (the left vertical axis is the stress) and the dotted curves show the strain rate dependences versus strain (the right vertical axis is the strain rate). Herewith, the curves with the same markers (solid lines and dashed lines) correspond to a certain regime of loading.

According to the deformation diagrams the values of the mechanical characteristics of the material were determined: the maximum stress and the strain prior to the beginning of fracture which corresponds to the maximum stress at different strain rates. As a result of the experiments the dependencies of these mechanical characteristics on the strain rate were constructed. Herewith, taking into account that the strain rate changes during the deformation, the maximum value of the strain rate prior to the beginning of fracture in each test was taken to plot the empirical relationships. The plotted dependencies indicated that with increasing strain rate the maximum stresses and the strain prior the beginning of fracture increase (Fig. 3a, 3b). This tendency was observed in the testing of other brittle materials, for example [15-17].

By integrating the curves obtained in the axes stress versus strain it is possible to calculate the value of the specific energy necessary for deformation and subsequent fracture of the sample. The average graphs of the energy intensity of the deformation process obtained under conditions of complete fracture of the samples are shown in Fig. $2 \mathrm{~b}$. The solid lines show the dependences of energy versus strain (the left vertical axis is the specific energy) and the dotted lines show the dependences of strain rate versus strain (the right vertical axis is the strain rate). Curves with the same markers (solid lines and dashed lines) correspond to a certain regime of loading. It is evident that the curves of specific energy versus strain are nonlinear and with an increase of strain rate in order to achieve a certain amount of strain it is necessary to apply more work of force.

The energy was determined, which was spent to deform the sample until the stress reached its maximum value (fracture energy) on the basis of the obtained deformation diagrams and energy intensity graphs. The dependence of the fracture energy versus the strain rate is shown in Fig. 3c. It is clear that the energy capacity of the material increases linearly while the strain rate increases. 


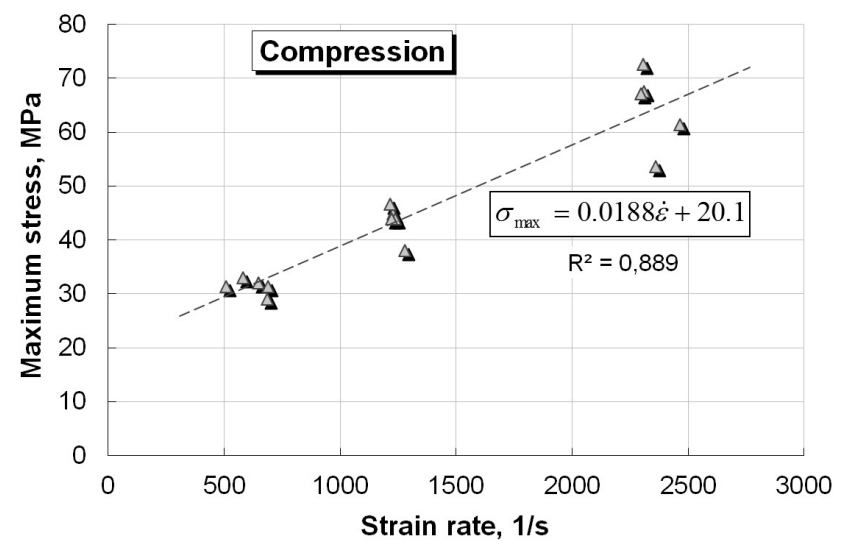

a

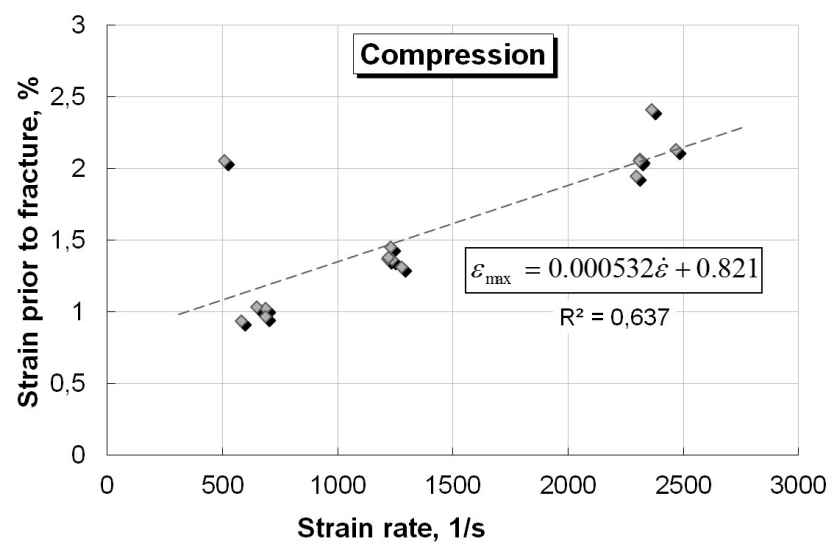

b

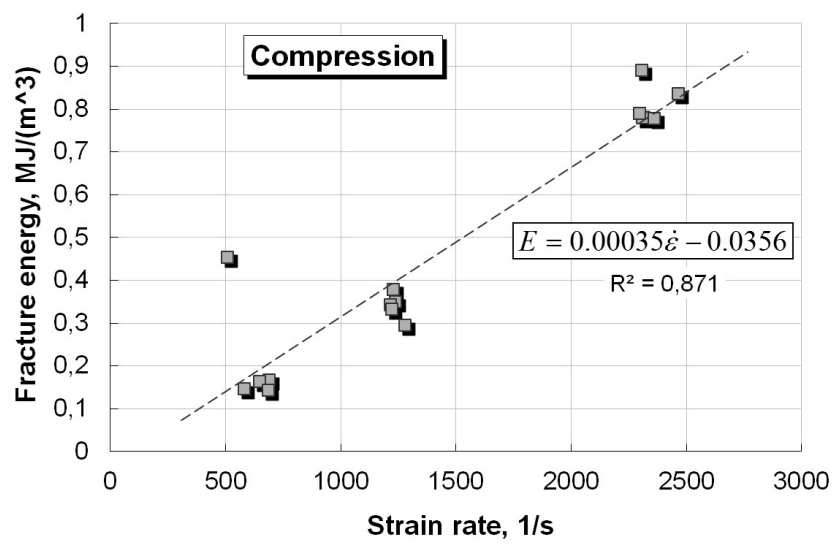

$\mathrm{c}$

Fig. 3. Dependencies of maximum stress (a), strain (b) and energy (c) before the beginning of fracture on the strain rate under compression 


\section{Results of dynamic tensile (splitting) tests}

Dynamic tensile (splitting) tests (or the so-called «Brazilian test») were carried out on cylindrical samples with a diameter of $20 \mathrm{~mm}$ and a length of $20 \mathrm{~mm}$. The amplitude of the loading wave was changed in experiments by varying the velocity of the cylindrical striker $20 \mathrm{~mm}$ in diameter and $300 \mathrm{~mm}$ in length. The analysis of this technique was carried out in [11] where it is noted that the «Brazilian test» can be used to determine the tensile strength of brittle materials when the elastic behaviour of the material and the state of equilibrium deformation of the sample are observed and its fracture occurs along the diametrical plane. To assess the implementation of these conditions, time history of the synchronized pulses of strain of the measuring bars was examined which showed the practical equality of forces acting on the lateral surfaces of the sample that causes the state of equilibrium deformation. The ends of the measuring bars were covered with a thin layer of grease before the test to reduce the effect of frictional forces on the process of deformation of the sample. In addition, the crack formation or complete fracture of the samples into two halves occurred along a diametrical plane (Fig. 4).

The average time history of the tensile stress obtained for different loading regimes of the sample under the velocity of the striker are shown in Fig. 5. In addition the values of the mechanical properties of the material: the maximum stress and the time prior to the beginning of fracture corresponding to the maximum stress at different stress rates were determined on the basis of the time history of the tensile stress in each test. The plotted dependences of these mechanical characteristics on the values of the stress rate showed that the strength of material increases (Fig. 6a) and the time prior to the beginning of fracture decreases (Fig. 6b) with the stress rate increasing.

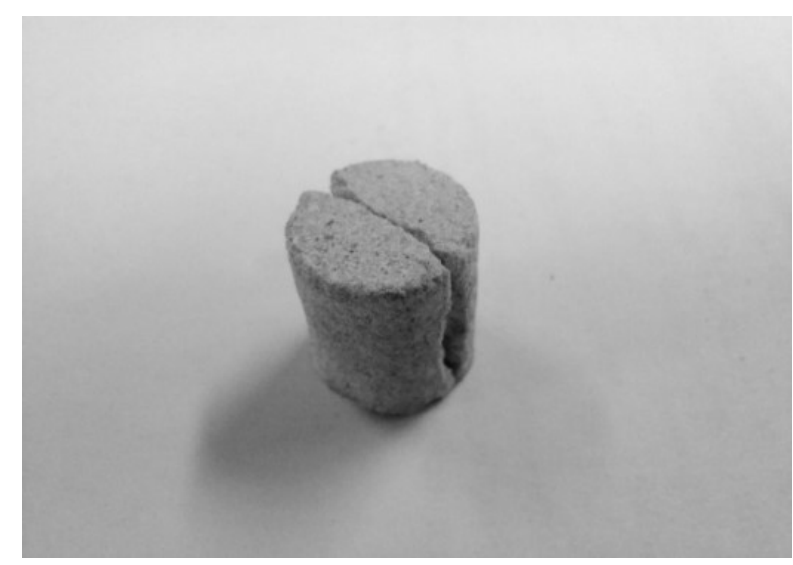

Fig. 4. The sample of a lime-sand brick after splitting test 


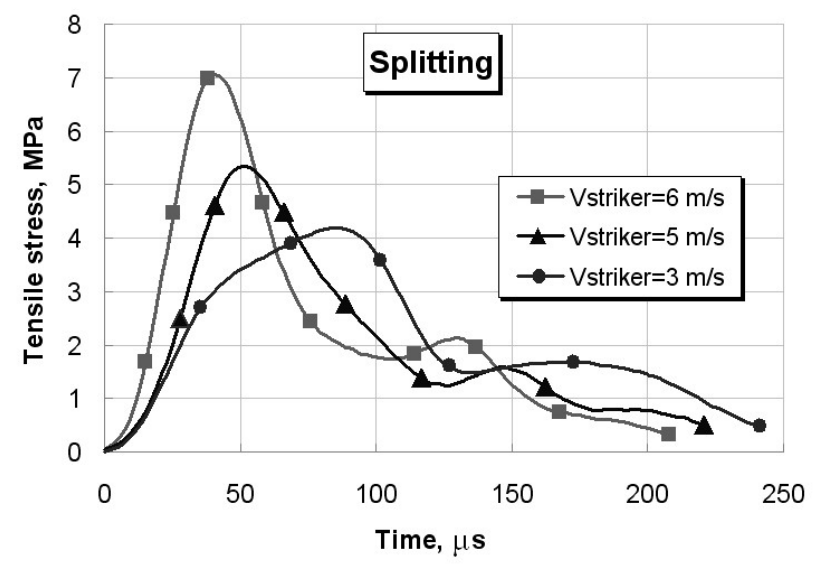

Fig. 5. Time dependences of the tensile stress of samples of lime-sand brick at splitting

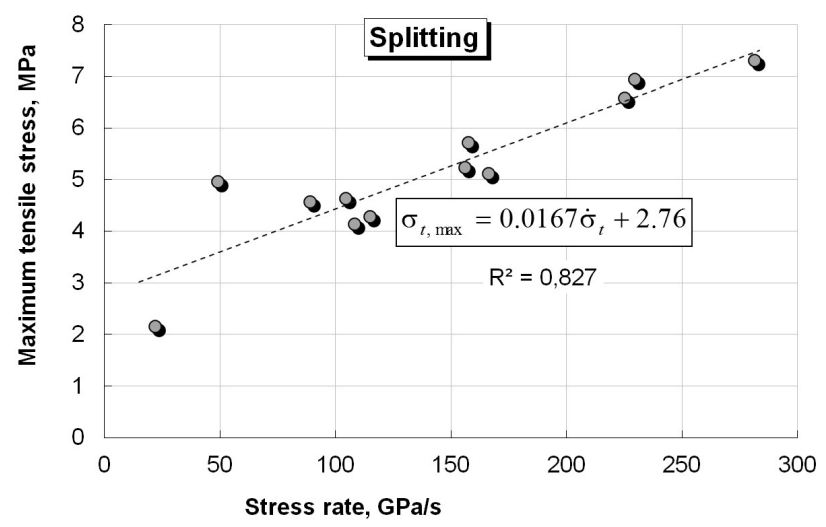

a

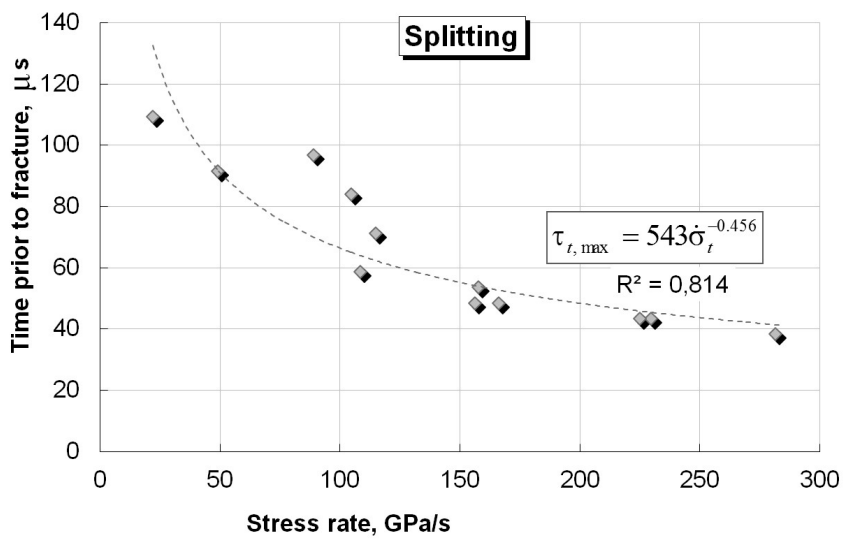

b

Fig. 6. Dependencies of maximum tensile stress (a) and time before the beginning of fracture (b) on the stress rate in splitting 


\section{Conclusions}

Uniaxial compression and tensile (splitting) tests with the use of the Kolsky method and its modification were carried out for samples from lime-sand brick grade 150. The obtained experimental results are characterized by a temperate scatter and show the influence of the strain rate and the stress rate on the strength, strain, time properties and energy intensity of the tested material (the values of the reliability of the approximation are shown in the graphs). Herewith, an increase in strength, strain prior to fracture and energy intensity are observed with an increase of the strain rate under compression. An increase in strength and decrease in time prior to fracture are observed with an increase of the stress rate under tension.

The research was carried out at the expense of the grant of the Russian Science Foundation (project № 17-79-20161).

\section{References}

1. P.H. Bischoff, S.H. Perry, Materials and Structures 24, 425 (1991)

2. H. Xu, H.M. Wen, International Journal of Impact Engineering 60, 76 (2013)

3. K. Xia, W. Yao, Journal of Rock Mechanics and Geotechnical Engineering 7(1), 27 (2015)

4. F. Zou, Z. Fang, M. Xia, Mathematical Problems in Engineering 2016, 11 (2016)

5. R.J. Thomas, A.D. Sorensen, Construction and Building Materials 153, 846 (2017)

6. H. Kolsky, Proc. Phys. Soc., 62B (1949)

7. A.M. Bragov, A.K. Lomunov, International Journal of Impact Engineering 16(2), 321 (1995)

8. A.M. Bragov, G.M. Grushevsky, A.K. Lomunov, DYMAT Journal 1(3), 253 (1994).

9. A.M. Bragov, A.K. Lomunov, I.V.Sergeichev, Journal of Applied Mechanics and Technical Physics 42(6), 1090 (2001)

10. A.M. Bragov, A.K. Lomunov, A.Yu. Konstantinov, D.A. Lamzin, Technical Physics Letters 43(1), 130 (2017)

11. T. Rodriguez, C. Navarro, V. Sanchez-Galvez, Journal de Physique IV 4, 101 (1994)

12. Q.M. Li, H. Meng, International Journal of Solids and Structures 40, 343 (2003)

13. M. Zhang, H.J. Wu, Q.M. Li, F.L. Huang, International Journal of Impact Engineering 36, 1327 (2009)

14. Q.M. Li, Y.B. Lu, H. Meng, International Journal of Impact Engineering 36, 1335 (2009)

15. A.M. Bragov, A.Y. Konstantinov, D.A. Lamzin, A.K. Lomunov, B.L. Karihaloo, Y.V. Petrov, I.V. Smirnov, Journal of Applied Mechanics and Technical Physics 53(6), 926 (2012)

16. A.M. Bragov, Yu.V. Petrov, B.L Karihaloo., A.Yu. Konstantinov, D.A. Lamzin, A.K. Lomunov, I.V. Smirnov, Engineering Fracture Mechanics 110, 477 (2013)

17. A. Bragov, B. Karihaloo, A. Konstantinov, L. Kruszka, D. Lamzin, A. Lomunov, Yu. Petrov, I. Vorobtsov, In: Proceedings of the 7th International Conference "Progress in Mechanics and Materials in Design» ed. by J.F. Silva Gomes, Shaker A. Meguid, Albufeira, Portugal, (2017). 